\title{
Stimulating and Supporting Change in Entrepreneurship Education: Lessons from Institutions on the Front Lines
}

\section{Elizabeth Nilsen, VentureWell}

Liz Nilsen is a Senior Program Officer at VentureWell, a national higher education network that cultivates inventions and technical innovations to improve life for people and the planet. At VentureWell, Liz provides leadership to the Epicenter Pathways to Innovation initiative, an effort to engage with a cohort of colleges and universities to fully embed innovation and entrepreneurship in undergraduate engineering education. She also works on the development of new programs for VentureWell. Liz previously led several STEM initiatives, including those associated with Penn State and Virginia Tech. She earned her BA from Stanford University and an MBA from Northeastern University.

\section{Ms. Victoria Matthew, VentureWell/Epicenter}

Victoria Matthew is Senior Program Officer for Faculty Development at VentureWell, where she plays a lead role in the Pathways to Innovation Program, Epicenter's faculty development and engagement strategy. She designs in-person and online convenings, engages experts, and curates content that fosters the Pathways faculty goals of integrating entrepreneurship and innovation into undergraduate engineering. Prior to joining VentureWell, Victoria worked for over a decade in higher education. She has designed, developed and managed degree, and certificate programs, and has experience as an online instructor, and mentor and trainer of other online instructors.

\section{Dr. Angela Shartrand, VentureWell}

Angela Shartrand is Director of Research and Evaluation at VentureWell, a non-profit higher education network that helps emerging scientists and engineers launch products and ventures that improve life for people and the planet. Since 2005, she has contributed to the growth and development of VentureWell's entrepreneurship and innovation initiatives, which include grants, competitions, faculty development, innovator training, and network building. In addition, she has collaborated on many NSF-funded projects that are advancing entrepreneurship education in STEM fields, including Epicenter and I-Corps $(\mathrm{tm})$. She and her team are currently examining the experiences of innovators commercializing and scaling-up new technologies, products, and services, and are developing ways to assess the venture and product development status of innovation teams. She received her B.A. from Williams College, an Ed.M. from Harvard University and a Ph.D. in Applied Developmental and Educational Psychology from Boston College.

\section{Dr. Thema Monroe-White, SageFox Consulting Group}

Thema Monroe-White is a senior evaluator at SageFox Consulting Group, specializing on driving organizational and program performance through efficient and effective evaluation design and implementation. Prior to joining SageFox, she worked as a researcher and evaluator for several local and federally funded projects in the areas of mental health, STI Policy and the STEM pipeline. Thema has also taught in the K-12 environment and served as an invited guest lecturer for courses in leadership, statistics and cross-cultural psychology at the undergraduate and graduate levels. Thema completed her PhD in Science, Technology and Innovation Policy at the Georgia Institute of Technology where she studied social entrepreneurship and innovation. She is a fluent Spanish speaker and world traveler having spent time in over one dozen countries since the age of nine. Thema currently lives in Atlanta, Georgia with her husband and three children. 


\title{
Stimulating and Supporting Change in Entrepreneurship Education: Lessons from Institutions on the Front Lines
}

\begin{abstract}
This paper describes Pathways to Innovation (Pathways), a national program that uses a team-based guided change process to help faculty and institutions introduce and embed innovation and entrepreneurship into formal and informal educational experiences for undergraduate engineers. The paper briefly reviews the program design, its researchbased foundations, and the sequence of activities for the initial cohort of twelve teams from twelve different schools. Initial results from teams' efforts, some of the "lessons learned" from the evaluation of the first year, and the implications of those lessons both for expansion of the program and for engineering education more generally are discussed.

Each school's Pathways effort is led by a team ${ }^{1}$ and the teams themselves are in turn gathered into a national network. ${ }^{2}$ The schools vary widely in their institutional profile with regard to size, student demographics, governance, initial breadth of entrepreneurship education opportunities for engineering students, and availability of off-campus entrepreneurship opportunities in the surrounding region. Despite these differences, multiple factors were identified over the course of the program year that were associated with success in making entrepreneurship education more available and accessible for undergraduate engineering students. Participating schools implemented strategies that included introducing new courses and programs, developing learning spaces, and creating faculty development activities. Program staff modified elements of Pathways in response to formative evaluation activities, as well as to strengthen specific components associated with team success. The program now includes 37 schools and will continue to expand; while exciting, this growth presents scaling challenges for program staff.
\end{abstract}

\section{Program Approach}

\section{Program Development}

The Pathways to Innovation program (Pathways) is a faculty development and institutional change initiative of the Engineering Pathways to Innovation (Epicenter) project - an initiative borne out of the growing realization that $21^{\text {st }}$ century engineers need to be equipped with new kinds of knowledge and skills to effectively operate in a world marked by rapid technological innovation. ${ }^{3}$ Students as well recognize that they need to know how to "collaborate effectively as leaders, in teams, and with their peers. In addition to their technical and analytical expertise, they need to be flexible, resilient, creative, empathetic, and have the ability to recognize and seize opportunities" (p. 36). ${ }^{4}$

Over the last decade, the Epicenter partners have seen visionary faculty champions make efforts to integrate these $21^{\text {st }}$ century skills into the curriculum in an incremental fashion (adding a course or launching an elective program). However, the partners involved with the Epicenter project observed that deeper change and sustainability did not directly follow these efforts. Existing efforts to stimulate entrepreneurship had clearly had some 
impact, but the overall landscape of engineering education had only shifted to a small degree.

Pathways program development began with an independent literature review to identify promising models and practices that could guide the design and implementation of a program that could foster deeper, more sustainable change. ${ }^{5}$ The major recommendations of that review included:

- Make the intervention long enough to support multiple learning activities and allow changes to be institutionalized.

- Ensure that learning theory and principles of instructional design are central to the faculty development components.

- Carefully select leaders of the change efforts at participating schools and provide them with ongoing training and support to fulfill that role effectively.

- Help faculty understand the substantial benefits to becoming part of a change effort.

- Create a well-structured evaluation effort that is an integral part of the project, providing interim data about the effectiveness of specific interventions and activities, and more summative information about the extent to which the program is producing desired faculty development and institutional transformation outcomes.

In response to these recommendations, program staff developed a theory of change to guide selection of program activities (a summary is shown in Exhibit 1).

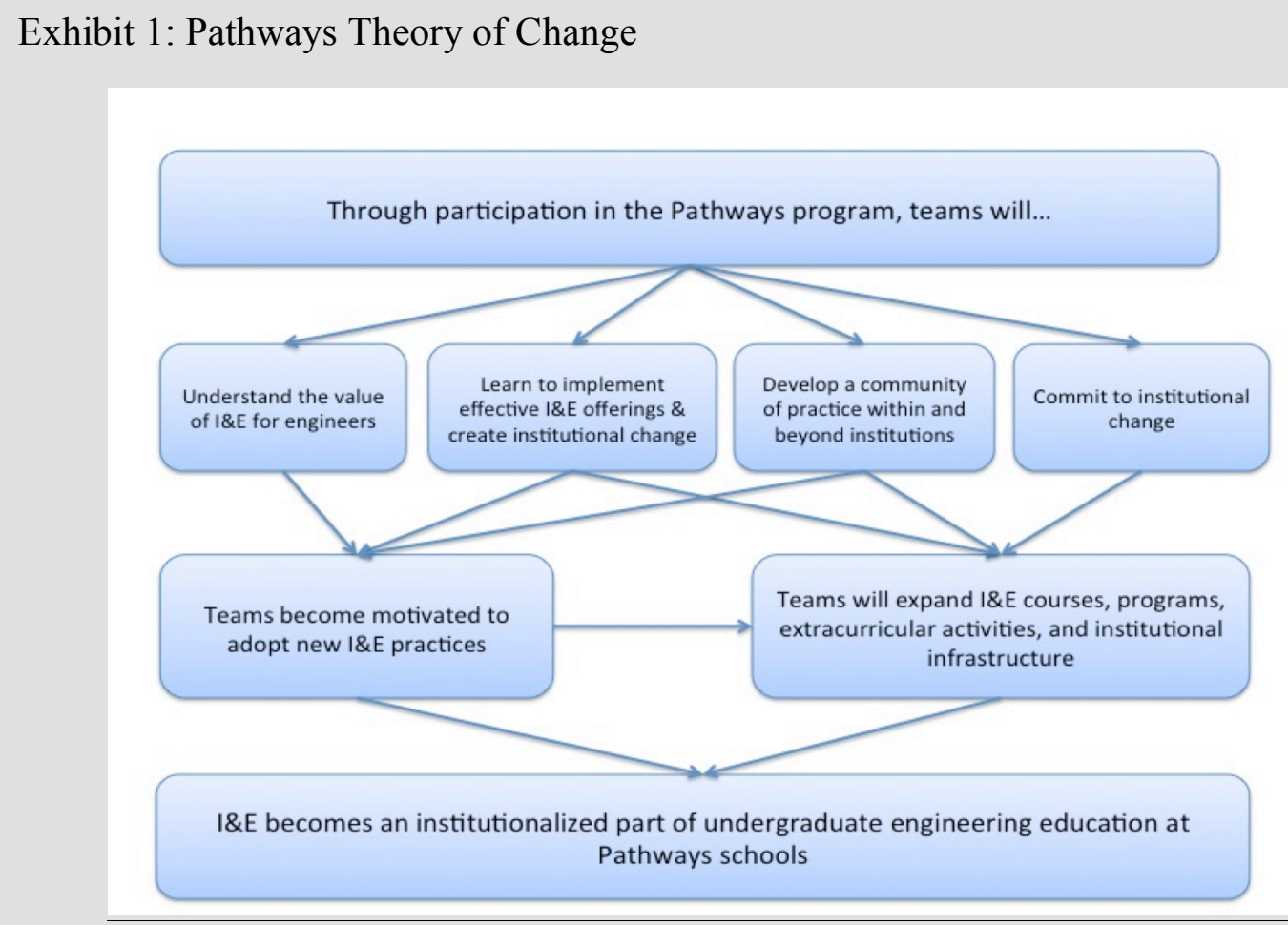


Implicit in the recommendations and the resulting theory of change is the principle that both individual and institutional behaviors drive the existing engineering education paradigm and its desired end state: faculty need new pedagogical techniques, exemplar curricula, and assessment strategies." However, moving beyond individual efforts and embedding innovation and entrepreneurship fully into the undergraduate engineering experience requires an equally intentional and supported effort toward "institutional change."

\section{Participating Schools}

The first twelve schools were selected to begin the program in late 2013; an additional 25 schools joined Pathways in late 2014. The schools represent a range of four-year institutions, as shown in Exhibit 2, representing institutions that are both public and private, of varying size, and include both research institutions and smaller colleges. Ten of the 37 schools are minority-serving institutions.

\section{Exhibit 2: Participating Schools Profile}

\begin{tabular}{|l|l|l|l|}
\hline \multicolumn{1}{|c|}{ Governance } & \multicolumn{1}{|c|}{$\begin{array}{c}\text { Carnegie } \\
\text { Classification }\end{array}$} & \multicolumn{1}{|c|}{ Region } & \multicolumn{1}{c|}{$\begin{array}{c}\text { Size (number of } \\
\text { undergraduates) }\end{array}$} \\
\hline Public: 27 & Research: 30 & South: 13 & $<5,000: 6$ \\
Private: 10 & Master's: 6 & Mid-Atlantic/Northeast: 8 & $5,001-15,000: 17$ \\
& Baccalaureate: 1 & $\begin{array}{l}\text { Midwest: } 8 \\
\text { West: } 8\end{array}$ & $\begin{array}{l}15,001-25,000: 10 \\
\end{array}$ \\
& & & $25,000: 4$ \\
\hline
\end{tabular}

\section{Program Structure}

Pathways schools are chosen through a competitive process in which they prepare a proposal describing their existing innovation and entrepreneurship activities for undergraduate engineers, their goals for participating in the program, and the core team that will lead the change effort. Teams include both faculty and administrators, and are drawn from multiple departments. While not a requirement of the program, many teams are interdisciplinary, including faculty from business, architecture, arts and design, or other STEM fields. The proposals identify a leader or two co-leaders, at least one of which is an engineering faculty member.

To demonstrate institutional support for the change effort, proposals must be accompanied by letters of support. The dean of engineering's letter confirms two important elements of the school's commitment: first, the school must make at least $10 \%$ of the team leader's time available to work on the Pathways project. Second, Pathways is not a grant program; financial support to the participating schools is limited to travel stipends for official Pathways gatherings (described below). The dean's letter thus also commits to cover any additional travel costs. 
To ensure support at the very highest level of the institution, a letter from the president of the university is also required. Finally, to facilitate future assessment efforts by the school's team, a letter of support from the director of institutional research is required.

Once selected, Pathways schools are part of a multi-faceted initiative that includes several different interventions to help fully embed innovation and entrepreneurship into the undergraduate engineering experience. The initiative's activities are summarized in Exhibit 3.

\section{Exhibit 3: The Pathways Program Structure}

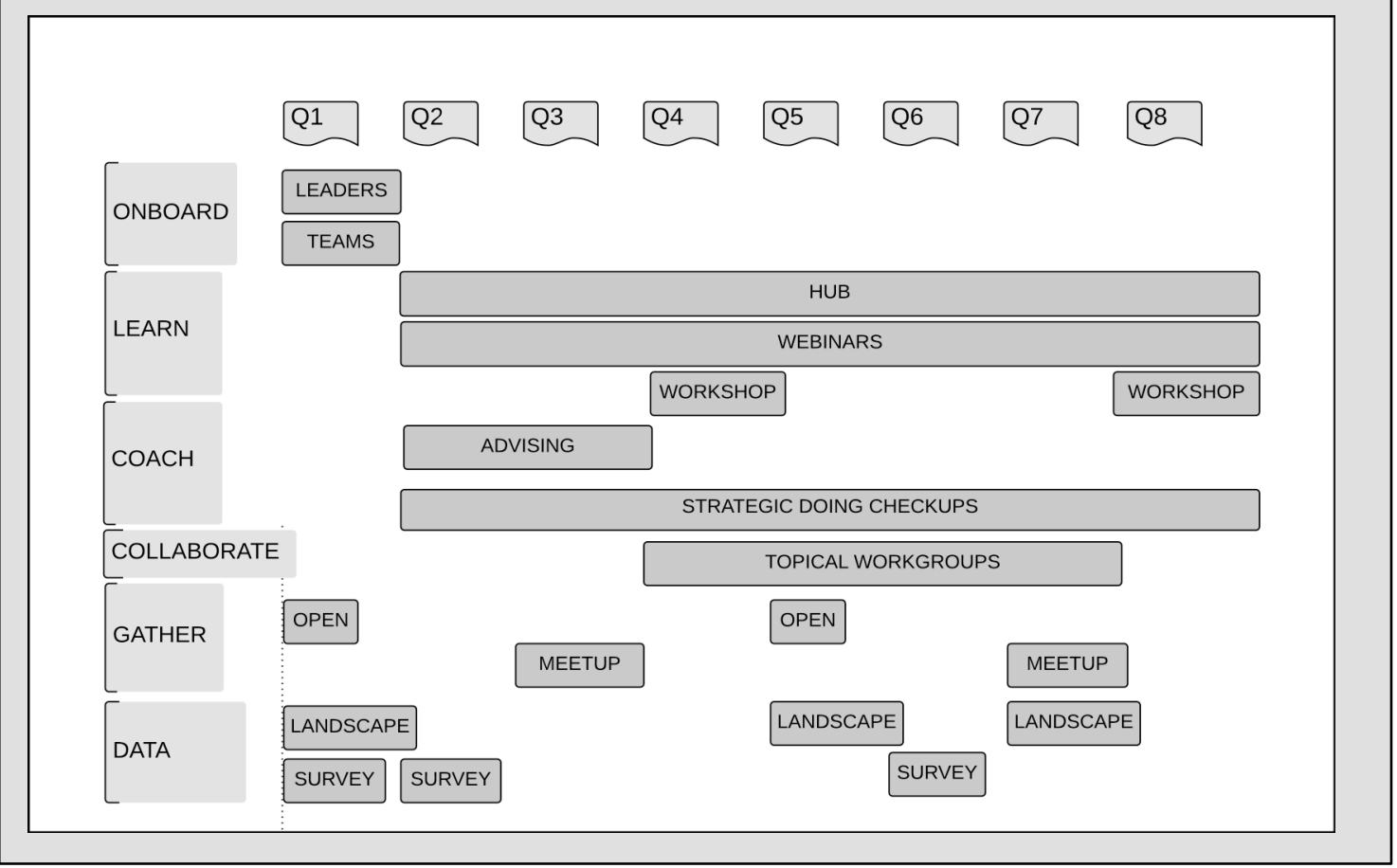

Onboarding: Team leaders attend an orientation session to prepare them for their role. The day-long meeting introduces leaders to the philosophy of the program, using the five components of an effective university entrepreneurial ecosystem described by Graham (see Exhibit 4 for examples). ${ }^{6}$ Other activities focus on leadership skills. The leaders are familiarized with their team's first assignment, a "landscape analysis" that describes in detail the innovation and entrepreneurship "assets" at their institution. 


\section{Exhibit 4: Components of University Entrepreneurial Ecosystems}

\begin{tabular}{|l|l|}
\hline \multicolumn{1}{|c|}{ Element of effective ecosystem } & \multicolumn{1}{c|}{ Examples } \\
\hline $\begin{array}{l}\text { University-Led Entrepreneurship and } \\
\text { Innovation Activity }\end{array}$ & Formal courses, programs, and spaces \\
\hline Leadership and Institutional Governance & Stated mission, presidential initiatives \\
\hline Academic Culture and Careers & $\begin{array}{l}\text { Tenure and promotion policies, support of } \\
\text { faculty development }\end{array}$ \\
\hline $\begin{array}{l}\text { Student-led and Grassroots Entrepreneurship } \\
\text { and Innovation Activity }\end{array}$ & Clubs, pitch competitions \\
\hline $\begin{array}{l}\text { Regional and National Innovation and } \\
\text { Entrepreneurship Activity }\end{array}$ & $\begin{array}{l}\text { Regional incubators, venture capital } \\
\text { availability }\end{array}$ \\
\hline
\end{tabular}

Based on Graham, R. Creating university-based entrepreneurial ecosystems evidence from emerging world leaders. (Massachusetts Institute of Technology, 2014)

A month later, four to five members of each team bring results from their landscape analyses to a multi-day workshop. Presenters from a wide variety of universities introduce Pathways teams to model programs in innovation and entrepreneurship. These sessions are interspersed with an introduction to a specific planning and change process called "strategic doing." Based on "lean" principles, strategic doing emphasizes rapid, iterative activities based on well-defined strategic outcomes. Teams produce an "alpha" (draft) plan, receive peer feedback, and revise their work for a "beta" version to take back to campus and begin the implementation process. Because teams are likely to expand (or change) as their work takes hold at the institution, a virtual "orientation" process is under development for new team members.

Learning: Faculty members from each Pathways school are offered the opportunity to participate in both virtual and in-person learning experiences. First, the "Pathways Hub" (pathways.epicenterusa.org), the online platform for the program, includes a resource library of syllabi, research papers, suggested websites, and the like. Second, monthly webinars for all interested faculty focus on topics identified by the teams (the first year's offerings included "maker spaces," fundraising for innovation and entrepreneurship, creativity, and IP policies). Webinars are recorded and are available along with ancillary resources on the Hub. Finally, each team has the opportunity to send faculty to at least two in-person faculty development workshops, the content of which is determined by teams' needs.

Coaching: Pathways teams receive two kinds of coaching, delivered through advising and strategic doing meetings. In both cases, teams are organized into "peer groups," each of which are comprised of teams from four schools, providing the opportunity to build 
strong relationships with a smaller number of colleagues. At the team-planning workshop, each team is asked to identify teams they would like to work with based on their interactions over that two-day gathering. Those preferences inform peer group formation.

Peer advising groups are facilitated by a Pathways staff member, and led by a faculty advisor. Advisors are selected based on their experience designing or managing a wellestablished innovation and entrepreneurship program. Peer group teams meet monthly via videoconference to share and troubleshoot the challenges they are encountering. The advisor suggests ways to overcome challenges, and encourages other peer group members to share their own insights and experiences. The sessions enable teams to gather advice and feedback that they can adopt and implement. Following these meetings, the facilitator gathers resources related to topics discussed and posts them to the Pathways Hub. Both the facilitator and the advisor recommend individuals or organizations that might provide additional insights. Topics discussed also provide ideas for upcoming webinars.

Like advising meetings, strategic doing meetings are regularly-scheduled video conference calls. However, their purpose is to focus on the iterative "strategic doing" process and cultivate peer accountability. Each team leader prepares a short presentation, using a scripted template (a "strategy map") that is uploaded to the Hub before the meeting. The map is structured around the team's self-identified strategic priorities, and guides team leaders in reporting where they are in the institutional change process, describing next steps, and soliciting advice on barriers encountered.

Collaboration: After the initial six months of teamwork, during which some false starts and "pivots" are expected, the advisory structure transforms into a different kind of collaborative work. Teams identify topical interest areas they would like to pursue, and based on those plans, virtual groups form to address common goals (for example, a group might form to work on redesigning a particular course common to multiple institutions), with a "deliverable" for their work together chosen by the group members. The timing of this transition to workgroups takes advantage of the academic calendar - the groups begin as the teams prepare for implementation of new or re-tooled courses and activities in the next fall term and the following spring term and have sufficient experience to best benefit from this work format.

In-Person Gatherings: The "community of practice" environment helps teams to stay on track and build momentum. An additional opportunity to reinforce this community - and integrate Pathways teams into a broader and less structured community of like-minded faculty - is participation in Open, VentureWell's annual conference, which brings together hundreds of faculty members who are interested in teaching innovation and entrepreneurship. The conference program focuses on methods, materials, and processes to support innovation and entrepreneurship teaching and learning. Sessions range from paper presentations to active workshops, and the event as a whole provides opportunities to interact with peers and student innovators. 
With a group of more than 35 Pathways schools now distributed across the country, the program may also launch regional meetups in 2015, to provide additional momentum and further sustain the peer-to-peer dimension of the program.

Data Gathering/Research \& Evaluation Activities: Research and evaluation activities occur throughout the program. These activities begin with two baseline assessments. The first is the landscape analysis assignment that the team completes at the very beginning of their participation; the second is a survey from the project's external evaluators, completed by all team members. Following these foundational activities, evaluation activities include post-event feedback after in-person gatherings and webinars, and two focus group opportunities (one at Open and another near the end of the team's first year). The teams also update their landscape inventories to provide a comprehensive look at what has changed on campus, every six months beginning in the second year.

Pathways managers and evaluators worked collaboratively to develop the programs' initial logic model and evaluation plan with these considerations in mind (see Exhibit 5 for evaluation questions). Questions were designed to capture evidence of institutional change using the Pathways team as the primary unit of analysis.

\section{Exhibit 5: Evaluation Questions}

1. Regarding the teams' early indicators for potential impact:

a. Do teams see the value in Pathways activities for achieving their own goals?

b. Do teams value being part of a collaborative group, going through this together? What are the perceived advantages of the group, if any?

c. Do teams have clarity around why they are participating, what the opportunity is for them, and what they hope to accomplish?

d. Do teams have clarity around the program's activities and theory of change?

e. Do teams have clarity around roles and responsibilities of their internal teams?

f. Are teams aware of what support is/isn't available from Epicenter?

2. Is Pathways an effective process for affecting change on a campus/culture, meeting participants' objectives?

3. Is Pathways an effective process for meeting Epicenter's objectives?

4. What aspects of Pathways are most scalable?

5. Did teams effectively apply new knowledge and skills?

6. Did teams effectively utilize the resources provided?

7. Are faculty, administrators and leaders throughout the institution better advocates for incorporating innovation and entrepreneurship into undergraduate engineering education?

\section{Program Results}

The evaluation plan for Pathways was developed with input from three primary stakeholder groups: 1) program managers, 2) the internal evaluation team, and 3) the external evaluation team. Data was collected using a combination of surveys, interviews, focus groups, and artifacts and reports generated by teams (e.g., landscape analyses, strategic doing plans, etc.), as well as periodic progress reports provided by the team leaders.

The first year evaluation efforts of the Pathways program were designed primarily to provide information for program improvement. ${ }^{8-11}$ This "formative feedback" 
program managers with early information and advice during the developmental stage of the program. Evaluation activities for the Pathways program were divided between the internal and external evaluation teams. Internal evaluation activities were guided by VentureWell staff to ensure consistency and alignment with VentureWell's organizational evaluation efforts. These activities were primarily survey-based and designed to collect immediate post-event feedback on specific program activities (i.e., onboarding sessions, meetups etc.). External evaluation activities were led by SageFox Consulting Group, with the aim of gathering feedback on the program's overall impact at the faculty and institutional level. The presence of an external evaluator also provided teams an opportunity to openly and honestly discuss potential areas of improvement as well as conduct more in-depth analyses of participant experiences (via site visits and indepth interviews). This distribution of labor made for an effective balance of activities and allowed program managers to remain active in all aspects of evaluation. Likewise, both the internal and external evaluation teams collaborate on the design of data collection instruments (surveys, interview protocols etc.) to ensure that multiple stakeholder needs are being met, and that feedback is well received by program staff.

Key findings from the first year's evaluation efforts included:

- Members preferred in-person gatherings and personal contact to online communications. In-person gatherings allowed teams to interact with and profit from the lessons learned at other institutions (either from guest speakers or other Pathways teams). In-person gatherings also allowed members to coalesce as a team and to concentrate on and catalyze ideas for immediate use at their institutions. Team members also valued the contact they had with program staff and wanted to feel connected to Epicenter leaders. The opportunity to connect with faculty experts from schools with long-standing programs was particularly valued.

- Teams valued being part of a cohort of twelve institutions. Members explained that it is "small enough for group accountability and sharing" and allowed for peer feedback. It also gave teams the ability to learn from the knowledge gained at other institutions.

- Pathways teams valued the resources available through the program and found them useful in achieving their goals, but also wanted to learn from other

institutions. Teams expressed a strong desire to know what other institutions have attempted, implemented, modified etc. on their paths to success and failure.

- The structured process of "strategic doing" required teams to persevere in their work and propelled the institutions forward. Teams credited the accountability associated with strategic doing for their progress.

- Participants valued the peer advising experience. Participants appreciated these meetings for the ability to connect and share with others as well as the accountability it provided. That said, evaluation revealed a temporal component: some teams did not feel ready to participate, and others were eager to move address specific challenges as opposed to more general concerns. 
This formative data was supplemented by the emergence of preliminary impact information, as teams completed their initial objectives and began to expand their efforts. Exhibit 6 summarizes the kinds of projects the teams began in their first year and the scope of impact reported to date.

\section{Exhibit 6: Projects Undertaken by Pathways Teams}

\begin{tabular}{|l|c|c|}
\hline \multicolumn{1}{|c|}{ Project type } & $\begin{array}{c}\text { Number of } \\
\text { projects } \\
\text { completed or } \\
\text { underway }\end{array}$ & $\begin{array}{c}\text { Total Undergraduate } \\
\text { Engineering Student } \\
\text { Enrollment at Participating } \\
\text { Institutions }\end{array}$ \\
\hline $\begin{array}{l}\text { New or substantially re-designed } \\
\text { courses }\end{array}$ & $\begin{array}{c}12 \text { (1 still in } \\
\text { development })\end{array}$ & 24,904 \\
\hline New non-credit workshops & 3 & 10,028 \\
\hline New or expanded makerspaces & $\begin{array}{c}7 \text { (2 still in } \\
\text { development })\end{array}$ & 10,672 \\
\hline $\begin{array}{l}\text { New or expanded student } \\
\text { competitions }\end{array}$ & $\begin{array}{c}5(1 \text { still in } \\
\text { development })\end{array}$ & 12,238 \\
\hline $\begin{array}{l}\text { Consolidations of dispersed } \\
\text { innovation and entrepreneurship } \\
\text { activity on campus }\end{array}$ & $\begin{array}{c}5(1 \text { still in } \\
\text { development })\end{array}$ & 5,295 \\
\hline $\begin{array}{l}\text { Credentials (certificates, majors, } \\
\text { minors) }\end{array}$ & $\begin{array}{c}2 \text { (still in } \\
\text { development })\end{array}$ & 1,768 \\
\hline $\begin{array}{l}\text { Improved infrastructure/policy (e.g. } \\
\text { classroom spaces, IP guidelines, } \\
\text { formal faculty development } \\
\text { programs) }\end{array}$ & $\begin{array}{r}4(1 \text { still in } \\
\text { development })\end{array}$ & 10,178 \\
\hline
\end{tabular}

Enrollment figures from Fall 2012 enrollment as reported to the Integrated Postsecondary Education Data System (IPEDS).

With the first year of work completed in March 2015, teams are now compiling more detailed information about the impact of these new activities on students, faculty and institutions.

\section{Lessons Learned}

In addition to more granular data about activities at individual campuses or the experiences of team members within the program, the first year of Pathways illuminated several larger "lessons learned": 
Importance of Institutional Context: Informed by the literature review, the Pathways program was designed explicitly to enable teams to design their own strategy for institutional change, rather than prescribe a specific curriculum or approach to be adopted by all. The goal is to provide teams with a conceptual framework for an ideal ecosystem, examples and practices to effectively foster those ecosystems, and support to help schools embed innovation and entrepreneurship into undergraduate engineering in their own institutional contexts.

Providing flexible tools and processes for use in varying contexts is a principle that has continued to influence the program design. The landscape analysis tool is one example. The overarching purpose of the landscape analysis process is to have teams consider the strengths and gaps on their campuses. This process provides team members with a shared understanding of the unique opportunities and challenges on their campus, and forms a foundation on which to develop plans for growing their entrepreneurial ecosystem.

The tool was originally designed as a spreadsheet for teams to document "assets" on their campus (e.g., courses, extra-curricular offerings, spaces, champions). The tool also defined the terms "innovation"* and "entrepreneurship" to support shared understanding. Finally, the tool guided teams in reflecting on various dimensions of their schools' ecosystem as a whole - the balance between electives and required courses, and the balance between innovation and entrepreneurship topics.

While many Pathways teams found the process of completing the landscape analysis challenging, later feedback revealed that it had in fact provided a strong foundation for planning, which was the intended purpose. In year two, multiple sources of constructive feedback led to slight modifications to the tool itself to meet the critical documentation and observation needs of the Pathways teams, program staff and the external evaluators.

Most fundamentally, the tool was redesigned to more tightly align with the elements of effective entrepreneurial ecosystems described by Graham. ${ }^{6}$ The platform for the tool was also changed, moving from a Microsoft Excel spreadsheet that the team leader controlled to a Google spreadsheet that could be completed collaboratively. Whereas previously the tool had defined "innovation" and "entrepreneurship" for the teams, in an effort to foster a more campus-specific approach, the updated tool encouraged teams to articulate and come to a consensus on their own working definitions. In addition, some of the detailed information that was included in the original version proved to be of limited utility and

\footnotetext{
* Innovation: the result of a "complex thinking process that is used to transform creative ideas into useful products and services."

"Entrepreneurship: the process of an individual or group to "create and build a business or organisation from practically nothing; make things happen for themselves by accepting responsibility; turn set-backs into opportunities; see gaps; sense opportunities; maintain effort until objectives had been achieved; build founding teams of talents around them to complement their abilities in areas where they are less knowledgeable or skilled; initiate and do; have the know-how to find, marshal and control resources (often owned by others) and make sure they do not run out of money when they need it most and; take calculated risks, both personal and financial to then do everything they possibly can to turn the odds in their favour."13
} 
therefore was eliminated. Other elements that were previously referenced as important to consider were raised up as more integral elements in the landscape. For example, now participants are asked to determine where courses lie on the innovation education continuum (i.e., "innovation process" or "innovation outcomes" "). ${ }^{14,15}$ In addition, participants must determine the degree to which courses and programs integrate active learning, since active learning and particularly experiential learning are associated with greater student self-efficacy. ${ }^{16-20}$

By encouraging teams to use the landscape tool for broader purposes, teams often engage people beyond the core Pathways team in the process (e.g., faculty from other disciplines, students on campus, and off-campus partners). Engaging these stakeholders fosters awareness of a greater breadth and diversity of innovation and entrepreneurship options within their campus ecosystem. This approach also helps to foster cross-campus or interdisciplinary communication.

Another context-responsive process for the Pathways teams is the strategic doing approach. Strategic doing is designed for environments with several stakeholders operating in a loose network (rather than a rigid hierarchy). This characterization of the environment leads to an implicit principle that the solution must be unique to the network, and mediated through multiple stakeholders; in other words, it must be adaptive to the institutional context. Strategic doing is linked explicitly to the landscape tool; completing the tool is the "prerequisite" activity, as it makes gaps apparent and shows where ecosystems need attention. For example, how are courses and programs distributed along the process/outcome continuum? If a team decides at the outset to focus their efforts on programming and spaces that foster venture creation, but consult their landscape analysis and see that their existing courses and programs focus primarily on creativity, a misalignment becomes apparent. Similarly, if a team discovers experiential learning is not currently being utilized in a target course, this becomes a potential place to implement change. Strategic doing directs teams to act on these discoveries by choosing strategic outcomes based on the opportunities to "link and leverage" the assets identified in the landscape tool. Assets may be combined strategically or optimized to meet goals.

Strategic doing is based on an iterative process in which teams ask themselves a set of structured questions, from possibility ("what could we do?") to commitment ("what will we do?"). This sequence (shown in Exhibit 7) also helps teams identify achievable outcomes most appropriate to the school's context. The final question ("what's our $30 / 30$ ?") is an explicit call to plan for the next meeting in which the team will reflect on what they learned in the past 30 days and then adjust their plans as needed for the next 30 days.

\footnotetext{
ॠ Innovation inputs include creativity, design thinking, prototyping, etc., while innovation outcomes focus on entrepreneurship, new venture development, intrapreneurship, management of technology, business development, etc.
} 
Finally, the topical workgroups are intended to help teams act more effectively in the context of their own institutions. These groups were not part of the original Pathways model, and were developed as part of a revision of the advisor structure. The peer advising sessions support teams early on, when they often pivot dramatically from their original ideas and/or are working on implementing a single limited project, and provide feedback across all of the projects. Advisor support is very useful to groups as they begin their work, but by the six-month mark, teams have committed more fully to working on specific projects (in fact, most have taken on several). They are more certain about their strategy and how to organize themselves, and need less guidance from the advisors.

Based on formative feedback that pointed to this shift, the program design was adjusted. Peer advising groups continue to be a key program activity, but only for the first six to nine months of the teams' work. As teams near the one-year mark of program participation, they will instead form working groups based on specific topic areas. The goal of these working groups is to help teams implement their projects more independently and further develop mutual respect among peers.

Value of Community of Practice: Pathways teams undertake challenging work. While one or two champions can initiate curricular changes, passion and persistence alone rarely bring about lasting, institutionalized transformation. They must pay attention to the "...people who have to take part in the change and to the importance of creating community around that change." 21

The first year of Pathways has confirmed the importance (identified in the literature review) of a peer network in supporting organizational change. ${ }^{22}$ As a result of multiple efforts outlined below, the Pathways teams (both individually and as a collective) are beginning to show the signs of a community of practice, "engag[ing] in a process of collective learning in a shared domain of human endeavor" (p. 1).

The community is comprised of the individuals on teams from the different institutions as well as experts from trailblazing schools that serve a variety of major and minor roles, be that as presenters at in-person or online events or as advisors to peer groups of teams. This community can provide feedback on programs developed and approaches to change; they encourage and sustain each other when challenges are encountered. The importance the Pathways program places on community is evident in the design of the Pathways program activities, be they in-person or online.

Evaluation feedback from the first year's in-person kickoff gatherings quickly revealed that the teams most valued getting to know each other and engaging in small group discussions with both their peers and the presenters. Therefore, subsequent gatherings have been designed to maximize these features. Presentations emphasize experiential activities to maximize team engagement with each other and the content. "World Café" style discussions - in which short presentations are followed by small group conversations, with the topics chosen by the participants - are also featured. This approach is designed to foster connection with each other and the presenters, and to dig into the topics that are most engaging and relevant to them. This approach also aims to help participants form a more collegial connection with "experts" and feel comfortable reaching out to them for advice about how to act on the knowledge shared. 
Peer groups play a critical role in the Pathways model by providing teams with a small subset of schools with whom to form a stronger, collaborative bond in the context of the peer advising and strategic doing meetings. The focus on peer-to-peer feedback in the context of the advising and strategic doing meetings is designed to help teams come to appreciate the value, insights and experiences of their peers and their advisors, which again fosters community.

The monthly online webinars also emphasize the importance community-building and the ways in which the community includes both Pathways team members and "experts." The webinars are designed to take on more of an interactive, workshop format. Rather than having participants listen passively to an expert, the webinars are hosted on a video conferencing platform that allows presenters and attendees to be seen simultaneously; there is no "sage on the stage." Presenters begin with information about their experience and expertise, but "Q\&A" always makes up a large part of the discussion, allowing participants to develop a clearer understanding of how the strategies shared might apply on their campus. As such, these online webinars are not simply an opportunity to increase knowledge; they are an opportunity to foster a sense of community among the participants.

As part of the application process for Pathways teams, applicants are now required to include in their application the reasons why they want to be a part of the Pathways community of practice. Responding to this question sets the expectation that the community is important. It also provides the Pathways program managers with another way to determine the "fit" of the applicants.

Intentional efforts to build the Pathways community have been accompanied by more organically emerging relationships initiated by participants. For example, several Pathways teams reached out via email and phone to presenters from in-person and online sessions, and some participants arranged visits to presenters' home campuses to learn more about the work they were doing. Similarly, some teams reached out to their advisors outside of advising sessions, and inviting them to visit their campuses. For example, one team asked their advisor to present to upper level administrators and faculty about their approaches. Some teams keep in touch with each other outside of the context of program activities, seeking advice and working on shared projects. For example, two Pathways teams collaborated on a successful NSF grant proposal related to innovation and entrepreneurship programming specifically for new transfer students. Another Pathways team flew across the country with their dean to visit a peer Pathways campus to observe the host's approach to integrating entrepreneurship and innovation.

Critical Role of the Team Leader: The most successful Pathways teams have an effective team leader (or in some cases, co-leaders). The role is one that can be unfamiliar territory for a faculty member who heretofore has pursued a traditional academic career path. Pathways leaders must possess the ability to be directive, so that tasks are completed. But they must also collaborate effectively so team members feel included and others on campus want to join the effort. Some team leaders call on their natural leadership "instincts" to strike this balance; others must make a more conscious effort to bring these qualities to the guidance of their team. 
The team leader's position in the institution also influences team effectiveness. While there have not yet been enough teams to test the hypothesis, anecdotal evidence suggests that an administrator/faculty co-leader arrangement may prove to be the most effective. While faculty members have more credibility with other faculty, an administrator can more easily cut through institutional bureaucracy when needed.

Based on these preliminary observations from the first twelve Pathways teams, the recruitment materials for the second cohort of schools were more prescriptive about the kind of individual the school should recruit for the team leader position. The team leader workshop, which kicks off the program, was also re-designed to emphasize the leadership skills needed.

\section{Implications of Results}

For the Program: As this article is written, the program is tripling in size from twelve schools in the initial cohort to 37 as of April 2015. At least one more cohort will come under the current NSF support and interest in Pathways participation is growing beyond that. Given this rapid growth, program staff must consider which aspects of the program can be replicated on a broader scale - or indeed, which aspects are sustainable beyond the current funding cycle.

The emphasis on building a "community of practice," while chosen for effectiveness, has the additional benefit of creating a self-sustaining community. Assistance is available not just from program staff, but also from peers. As the Pathways community grows, this support is available more widely from the first schools in the program (for example, team leaders from the first group of schools attended the team leader training for the second group, and team leaders and team members are also beginning to present at other Pathways in-person events and webinars). The development of the Pathways Hub, with a growing collection of articles, recorded webinars, and sample curricula, is another element of the program that enables the initiative to grow. Finally, by not providing schools with implementation funding project funds can be stretched to include additional schools; this approach also lets prospective schools know that they will need to provide sufficient resources for the effort from the outset.

Some elements of the Pathways program model are difficult to scale and sustain. Evaluation data revealed that while teams appreciated opportunities to gather virtually, in-person gatherings were highly preferred. They are, however, highly resource-intensive, in terms of both staff time and funding. This is one reason the project team is considering implementing regional meetups as an alternative to some in-person gatherings. Another program element which presents challenges at scale is evaluation, specifically as it relates to collecting granular information about program impact at the level of each individual institution. Such information is important not just for the project as a whole, but also for individual teams as they advocate for additional resources for innovation and entrepreneurship on their campuses. A redesign of the landscape tool (to incorporate an "update" function to help gather current data, compare snapshots of the landscape over time, and compare landscapes across institutions) is now underway to help offset the challenges associated with not having tailored evaluations for each specific Pathways institution. 
For Engineering Education: To date, the experience and program evaluation data for Pathways suggests that while challenging, institutional change in engineering education may be possible through this promising program model. However, it is important to recognize that the program is still in a formative stage. Several implications for engineering education are noted here. First, while the program is still young and evidence of program impact on engineering students is still being gathered, a great deal has been learned about what has worked well and what has needed improvement in terms of program design and implementation. In particular, we have learned that cultivating communities of practice is essential to creating and supporting long-term sustainable change in engineering education. In particular, team leadership is critical, but those leaders must facilitate collaboration given that institutional change is necessarily a team effort. Finally, having advisors who have "been there" has been an important strategy for formalizing the transfer of knowledge and expertise to newcomers to this field. Ideally, this community will grow and expand, and the expectation is that the cross-institutional connections that are cultivated throughout the program will remain after formal participation in the program has ended. Ideally, the community will create new ways to work together, and will continue to share and develop their expertise.

\section{Acknowledgments}

This work is supported by the National Science Foundation: DUE 1125457.

\section{References}

1. Beach, A. L., Henderson, C. \& Finkelstein, N. Facilitating Change in Undergraduate STEM Education. Change Mag. High. Learn. 44, 52-59 (2012).

2. Dempster, J. A., Benfield, G. \& Francis, R. An academic development model for fostering innovation and sharing in curriculum design. Innov. Educ. Teach. Improv. 49, 135-147 (2012).

3. Duderstadt, J. J. Engineering for a Changing World. (University of Michigan, 2008).

4. Byers, T., Seelig, T., Sheppard, S. \& Weilerstein, P. Entrepreneurship: Its Role in Engineering Education. Bridge Link. Eng. Soc. 43, 35-40 (2013).

5. Giersch, S., McMartin, F., Nilsen, L., Sheppard, S. D. \& Weilerstein, P. Supporting Change in Entrepreneurship Education: Creating a Faculty Development Program Grounded in Results from a Literature Review. in ASEE Conference Proceedings (2014).

6. Graham, R. Creating university-based entrepreneurial ecosystems evidence from emerging world leaders. (Massachusetts Institute of Technology, 2014).

7. Eisenhardt, K. M. \& Sull, D. Strategy as Simple Rules. Harv. Bus. Rev. 79, 106-116 (2001).

8. Fitzpatrick, J. L., Sanders, J. R. \& Worthern, B. R. Program evaluation: Alternative approaches and practical guidelines. (Pearson Education, 2004).

9. Patton, M. Q. Developmental evaluation: applying complexity concepts to enhance innovation and use. (Guilford Press, 2011).

10. Creswell, J. W. \& Plano Clark, V. W. Designing and conducting mixed methods research. (Sage, 2011).

11. Standards-based and responsive evaluation. (Sage, 2004).

12. Scriven, M. Goals of evaluation versus roles of evaluation: Formative and summative evaluation. (AERA Monographs on Curriculum Evaluation, 1967).

13. Timmons, J. A. New venture creation: entrepreneurship for the 21st century. (Irwin, 1994).

14. Duval-Couetil, N. \& Dyrenfurth, M. Teaching students to be technology innovators: Examining approaches and identifying competencies. in American Society for Engineering Education Annual Conference (2012).

15. Duval-Couetil, N. \& Dyrenfurth, M. Teaching students to be innovators: Examining competencies and approaches across disciplines. Int. J. Innov. Sci. 4, 143-154 (2012). 
16. Duval-Couetil, N., Shartrand, A. \& Reed-Rhoads, T. The role of entrepreneurship program models and experiential activities on engineering student outcomes. Adv. Eng. Educ. (2015).

17. Neck, H. M., Greene, P. G. \& Brush, C. G. in Annals of entrepreneurship education and pedagogy 2014 (ed. Morris, M. H.) 3-20 (Edward Elgar Publishing, 2014).

18. Ohland, M. W., Frillman, S. A., Zhang, G., Brawner, C. E. \& Miller, T. K. I. The effect of an entrepreneurship program on GPA and retention. J. Eng. Educ. 93, 293-301 (2004).

19. PCAST STEM Undergraduate Working Group. Engage to Excel: Producing One Million Additional College Graduates with Degrees in Science, Technology, Engineering, and Mathematics. (Office of the President, 2012). at $<\mathrm{http}: / / \mathrm{www}$.whitehouse.gov/sites/default/files/microsites/ostp/pcast-engageto-excel-final_2-25-12.pdf>

20. Wheadon, J. \& Duval-Couetil. Analyzing the Expected Learning Outcomes of Entrepreneurship Business Plan Development Activities Using Bloom's Taxonomy. in Proceedings of the 2013 ASEE Annual Conference (ASEE/IEEE, 2013).

21. Goldberg, D. E. A whole new engineer: the coming revolution in engineering education. (ThreeJoy Associates, Inc, 2014).

22. Steinert, Y. et al. A systematic review of faculty development initiatives designed to improve teaching effectiveness in medical education: BEME Guide No. 8. Med. Teach. 28, 497-526 (2006).

23. Wenger, E. Communities of Practice: Learning, Meaning, and Identity. (Cambridge University Press, 2000). 